\title{
ANALISIS STRATEGI PENGEMBANGAN BISNIS UMKM WARTEG SEKITAR KAMPUS IBI KOSGORO 1957 JAKARTA
}

\author{
Reny Andriyanty \\ Program Studi Manajemen, Fakultas Ekonomi \\ Institut Bisnis dan Informatika (IBI) Kosgoro 1957 \\ Email: r.andriyanty@gmail.com
}

\begin{abstract}
ABTSRACT
Warteg is a food business based on rice and side dishes, which is Indonesia typish. The purpose of this research is to be able to formulate the spesific business strategy for the development of the warteg business around the IBI Kosgoro Campus 1957, South Jakarta. The research method is descriptive qualitative with data analysis methods applying SWOT analysis. The study recommend three strategies, namely: 1) providing hygienic and comfortable place, full music and television and food security-license, longer operating hours, 2) providing a fresh and varied menu every day and 3) setting low prices which are supported by digital payment technology applications.
\end{abstract}

Keywords: Warteg, Business Strategy, SWOT Analysis.

\section{PENDAHULUAN}

\subsection{Latar Belakang}

Salah satu komoditas sub sektor unggulan ekonomi kreatif di Indonesia adalah kuliner. Tujuan pengembangan kuliner Indonesia diarahkan pada pasar global dengan brand asli Indonesia. Dari tahun 2016 sampai tahun 201, sub sektor kuliner memiliki sumbangan atas pendapatan domestik bruto (PDB) dengan tren yang terus meningkat. Data rinci mengenai perkembangan tersebut dapat dilihat pada gambar berikut:

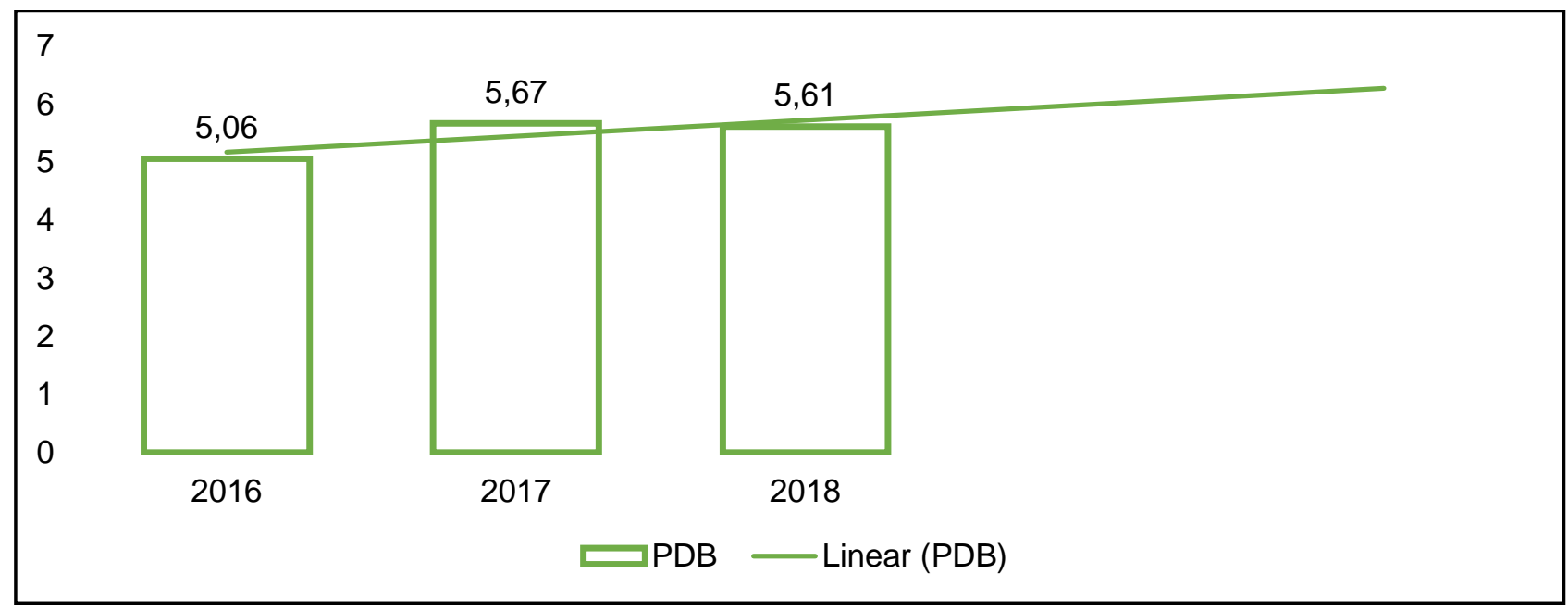

Gambar 1. Sumbangan Sub Sektor Kuliner Atas PDB Indonesia

Sumber : (Badan Ekonomi Kreatif RI, 2020).

Menurut BPS DKI Jakarta tahun 2020, sektor penyedia akomodasi dan makan minum merupakan sepuluh sektor teratas tahun 2020 memiliki kontribusi 90 persen pada pendapatan domestik regional bruto atas dasar harga berlaku (PDRB ADHB) DKI Jakarta (Badan Pusat Statistik, 2020). Hal tersebut menunjukkan besarnya potensi bisnis UMKM makanan dan minuman di DKI Jakarta. Usaha kuliner merupakan usaha yang banyak 
menyasar konsumen di perkotaan. Kebutuhan konsumsi masyarakat perkotaan saat ini sedang menyesuaikan dengan gaya hidup global dimana pola konsumsi untuk membeli makanan siap makan menjadi suatu kebiasaan umum (Sarwono, 2015).

Salah satu bisnis makanan siap jadi adalah "warteg". Warteg merupakan singkatan dari warung Tegal. Bisnis ini merupakan konsep bisnis warung makanan berbasis nasi dan lauk pauknya yang khas Indonesia. Warteg merupakan pilihan yang sangat terjangkau bagi seluruh kalangan pendapatan di perkotaan dan sampai tahun 2018 setidaknya terdapat 37.000 outlet tersebar di Jakarta, Bogor, Depok dan Tangerang. Peran warteg dalam kehidupan masyarakat menengah di perkotaan jelas sangat signifikan. Salah satu peran UMKM ini membuka lapangan pekerjaan dengan setidaknya melibatkan 134.000 pekerja non-formal (M.D. Novianti \& Susanto, 2018).

Warteg berasal dari desa Sidakaton, Krandon dan Sidapurna Kecamatan Dukuhturi Kabupaten Tegal. Awalnya warung ini merupakan warung tenda yang menjajakan berbagai macam lauk pauk dan nasi. Warteg pertama kali diperkenalkan di Jakarta oleh Pak Warno yang kemudian mentransformasi tampilan warteg menggunakan lemari kaca untuk menjaga kesehatan dan keselamatan pangan bagi konsumen. Warteg merupakan warung makan tradisional Indonesia dengan bentuk khas ruang persegi dan sederhana menggunakan meja etalase sebagai perkembangan meja gelar warung tenda. Tata ruang yang khas tersebut mengikuti sistem operasi bisnis di warteg yaitu: konsumen datang, memesan menu, makan/minum, membayar kemudian konsumen pergi (Khamdevi \& Nasution, 2014). Secara rata-rata warteg dapat menawarkan 10-20 menu per harinya yang diganti setiap hari dengan rata-rata harga pembelian adalah Rp.12.000-Rp.15.000 per piringnya. Pendapatan bisnis warteg secara rata-rata berkisar Rp.500.000 sampai Rp.3.000.000 per hari dengan rata-rata pendapatan Rp.1.000.000-Rp.2.000.000 per hari tergantung pada skala dan jam operasi usahanya (S. A. Santoso, 2019).

Besarnya prospek keuntungan per hari yang diperoleh dari bisnis ini membuat ketatnya persaingan bisnis antar warteg. Di sekitar kampus Institut Bisnis dan Informatika (IBI) Kosgoro 1957 terdapat dua warteg yaitu warteg Putra Kuningan dan warteg Berkah Bahari. Sebagai penyedia makanan yang terjangkau dan sehat bagi mahasiswa, keberadaan warteg ini sangat membantu aktivitas belajar mengajar bagi IBI Kosgoro 1957. Sehingga bisnis warteg yang berada di sekitar kampus ini perlu dikaji konsep bisnisnya untuk dapat bertahan menghadapi bisnis lain.

Analisis yang dilakukan Andriyanty dan Wahab (2019) mengenai preferensi konsumen muda atas produk makanan dan minuman menyimpulkan bahwa preferensi mereka dipengaruhi oleh harga, cita rasa, keinginan membeli makanan rumahan, kualitas dan kehalalan produk. Berdasarkan faktor-faktor tersebut, maka tim panel ahli membentuk matriks profil persaingan dari setiap warteg obyek penelitian. Hasil analisis menunjukkan bobot untuk setiap faktor kritis kehalalan memiliki bobot tertinggi $(0,30)$. Faktor kritis kedua adalah cita rasa, mutu, dan informasi kandungan gizi produk warteg berbobot 0,27 . Dan faktor kritis ketiga adalah harga produk (bobot 0,18 ).

Untuk dapat menilai bagaimana kemampuan bersaing warteg di sekitar kampus IBI Kosgoro 1957 dilakukan analisis penilaian profil persaingan antara warteg Putra Kuningan dan Berkah Bahari dapat dilihat pada tabel berikut: 
Tabel 1. Competitive Profile Matrix

\begin{tabular}{lccc}
\hline \multicolumn{1}{c}{ Critical Success Factors } & Bobot & Rating Rerata & Skor \\
\hline Warteg Putra Kuningan & & & \\
Cita rasa, mutu, informasi kandungan gizi mengenai produk & 0,27 & 3 & 0,75 \\
Harga & 0,18 & 2 & 0,56 \\
Halal & 0,30 & 4 & 1,08 \\
Kemasan \& Tata cara Penyajian & 0,13 & 3 & 0,34 \\
Kualitas pelayanan & 0,12 & 3 & 0,32 \\
\hline & Jumlah Rating x Bobot & $\mathbf{3 , 0 5}$ \\
\hline Warteg Berkah Bahari & & \\
Cita rasa, mutu, informasi kandungan gizi mengenai produk & 0,27 & 3 & 0,76 \\
Harga & 0,18 & 3 & 0,56 \\
Halal & 0,30 & 4 & 1,07 \\
Kemasan \& Tata cara Penyajian & 0,13 & 3 & 0,34 \\
Kualitas pelayanan & 0,12 & 3 & 0,35 \\
\hline
\end{tabular}

Sumber : Data primer diolah (2021).

Berdasarkan keterangan di atas menunjukkan bahwa warteg Berkah Bahari (nilai 3,07) lebih kompetitif dibandingkan warteg Putra Kuningan (nilai 3,05). Keunggulan bersaing warteg Berkah Bahari diperoleh dari faktor kritis cita rasa, mutu, informasi kandungan gizi mengenai produk dan kualitas pelayanan. Analisis di atas menunjukkan bahwa bisnis warteg yang berada di sekitar kampus IBI Kosgoro 1957 layak untuk dikembangkan. Pengembangan bisnis ini memerlukan suatu kajian manajemen strategi.

\subsection{Masalah}

Warteg adalah bisnis makanan yang dapat menyangga perekonomian di perkotaan. Warteg dapat menyediakan pangan murah bagi masyarakat sehingga keberadaannya sebagai bisnis berciri asli Indonesia harus dapat dipertahankan dan dikembangkan ke tingkat global. Namun konsep dan operasi bisnis yang belum terkaji secara akademik membuat riset dibidang UMKM ini kesulitan dalam menemukan konsep bisnis yang lebih jelas dan baku. Sehingga perlu dianalisis, strategi bisnis yang jelas untuk meningkatkan perkembangan bisnis warteg baik secara nasional dan bahkan sampai ke tingkat internasional.

\subsection{Tujuan}

Tujuan penelitian ini adalah untuk dapat memformulasikan strategi bisnis yang tepat bagi perkembangan bisnis warteg di sekitar Kampus IBI Kosgoro 1957 Jakarta Selatan.

\section{TINJAUAN PUSTAKA}

Warteg dapat diasosiasikan sebagai simbol ketahanan pangan masyarakat menengah ke bawah di Indonesia dan memiliki prospek untuk dikembangkan (Novianti, Susanto, Hatta, \& Johannes, 2018; Asytuti, 2015) Keunikan warteg yang sangat khas adalah tata letak meja makan sekaligus etalase sebagai display bahan makanan dengan bangku panjang serta terdapat beragam lauk pauk, harga murah dan dialek khas dari penjual yang berasal dari Tegal (M.D. Novianti \& Susanto, 2018; Khamdevi \& Nasution, 2014). 
Saat ini warteg masih dikategorikan dalam bisnis usaha mikro, kecil, dan menengah. Banyak tantangan yang dihadapi kelompok bisnis ini terutama saat pandemi covid-19 (Awaloedin, Sazali, Nurhilaludin, \& Hanifa, 2020). Sebagai UMKM, terdapat kendala internal dan eksternal yang teridentifikasi. Kendala internal adalah rendahnya akses mereka pada pembiayaan bisnis, rendahnya SDM, rendahnya kemampuan analisis pasar dan pemasaran, serta rendahnya kemampuan manajerial sistem administrasi bisnis. Sedangkan faktor eksternal yang harus diperhatikan adalah lingkungan bisnis yang kondusif bagi pelaku bisnis warteg, rendahnya akses pada teknologi informasi, rendahnya kemampuan mereka dalam mengakses bahan baku serta rendahnya kemampuan menangkap perubahan permintaan konsumen saat ini (A'yun, 2017; Herr \& Nettekoven, 2017; Muttalib, 2017; Neagu, 2016; Sarwono, 2015).

Penelitian Knox et al menunjukkan bahwa bisnis makanan skala mikro, kecil dan menengah menjadi sumber pendapatan di negara sub-sahara berbasis gender. Hal ini menunjukkan bahwa peran sektor ini memiliki potensi ekonomi. Dimana bisnis makanan jalanan atau jajanan dapat menjadi sumber pertumbuhan. Kebijakan yang dapat mendukung sektor ini adalah kebijakan berbasis penangkapan peluang dibandingkan mengembangkan kebijakan berbasis kebutuhan (Knox, Bressers, Mohlakoana, \& De Groot, 2019; Draper, 1996). Bisnis sektor ini terbukti secara empiris dapat mereduksi kemiskinan di perkotaan di negara-negara berkembang (Nirathron, 2006). Penelitian di Eropa menyatakan bahwa bisnis makanan kecil secara empiris dapat dikembangkan yang justru menjadi pengungkit sektor pertanian skala kecil. Hal ini menandakan perlunya integrasi bisnis yang saling terkait dan menguntungkan (Hernández et al., 2021).

Bisnis mikro, kecil dan menengah, memerlukan suatu strategi pengembangan bisnis agar bisnis makanan dapat bertumbuh terutama di negara-negara yang sedang berkembang (Hilmi, 2020; Hong \& Nguyen, 2020; Hiemstra, Van Der Kooy, \& Frese, 2006). Bisnis yang menerapkan manajemen strategi akan beroperasi lebih baik dibandingkan usaha lain yang tidak peduli pada strategi (Karel, Adam, \& Piszezur, 2013). Penelitian Charles et al yang dilaksanakan di Kenya menyatakan bahwa terdapat tiga strategi yang diterapkan bisnis skala mikro, kecil dan menengah. Secara umum strategi yang diimplementasikan adalah strategi tidak formal dan terbukti berhasil. Pertama, strategi yang disengaja dimana rencana bisnis diformalkan secara tertulis dan dijalankan dengan ketat. Strategi kedua adalah bisnis tanpa strategi formal dan berjalan sesuai pengalaman dan tradisi yang berlaku di industri tersebut. Strategi ketiga adalah bergantung pada naluri pemilik bisnis (Charles, Ojera, \& David, 2015).

\section{METODE PENELITIAN}

Metode penelitian adalah deskriptif kualitatif. Penelitian dilakukan dari bulan September 2020 sampai bulan Februari 2021. Lokasi penelitian adalah di jalan M. Kahfi II Kampus IBI Kosgoro 1957 Kecamatan Jagakarsa. Responden penelitian adalah pihak internal (pemilik warteg) dan eksternal (tim ahli dan konsumen warteg). Teknik analisis data menggunakan analisis SWOT (David, 2011). Kegiatan analisis data terbagi atas tiga kegiatan, yaitu: 
1) Tahap penginputan dengan teknik Delphi yang melibatkan pihak pemilik warteg dan empat panel kelompok ahli. Analisis faktor kunci eksternal dan internal menggunakan teknik Delphi. Langkah kegiatan yang dilakukan adalah:

- Pemilik warteg diwawancara untuk mendapatkan faktor kunci yang mempengaruhi bisnisnya. Penentuan faktor competitive profile matrix dibuat berdasarkan hasil penelitian Andriyanty \& Wahab yaitu Cita rasa, mutu, informasi kandungan gizi mengenai produk, harga, kehalalan produk, kemasan dan tata cara penyajian (Andriyanty \& Wahab, 2019).

- $\quad$ Pembuatan kuesioner terkait identifikasi faktor-faktor penting.

- $\quad$ Pemilihan konsumen kunci untuk mengisi kuesioner yang dikirim

- Mengirimkan rangkuman kuesioner kepada para panel ahli.

- Tim panel ahli diminta untuk menelaah ulang hasil rangkuman dan menetapkan skala prioritas atau memeringkat alternatif solusi yang dianggap terbaik. Dan proses ini kembali diulang sampai para panel ahli telah mendapatkan informasi yang dibutuhkan guna mencapai kesepakatan untuk menentukan satu alternatif solusi atau tindakan terbaik.

Setelah seluruh faktor eksternal dan internal kunci maka dihasilkan data EFE dan IFE. Pengujian kelayakan faktor kunci dilakukan dengan menggunakan content validity. Analisis validitas isi memastikan bahwa faktor yang teridentifikasi sudah memasukkan sekumpulan item yang memadai atau mewakili seluruh konsep yang dikembangkan dari analisis dari panel yang kompeten. Tes content validity menggunakan tes KaiserMeyer-Olkin Measures of sampling adequancy test. Uji content validity merupakan proses validasi yang melewati pengujian terhadap kelayakan dan relevansi konten melalui analisis rasionalitas oleh para panel ahli berkompeten dan atau expert judgement yang umumnya terdiri atas 3-7 ahli (Hendryadi, 2017; Mohajan, 2017; Yaghmaei F., 2003; Lawshe, 1975). Item dinyatakan valid jika nilai Kaiser-MeyerOlkin measures of sampling adequancy test lebih besar dari nilai 0,5. Untuk pengujian keandalan faktor-faktor kunci baik eksternal maupun internal digunakan tes cronbachalpha. Nilai faktor kunci akan reliabel jika nilai cronbach alpha lebih besar dari 0.7.

2) Tahap penyesuaian. Setelah seluruh faktor kunci dinyatakan valid dan reliabel, maka dilakukan uji pembobotan. Uji pembobotan yang digunakan adalah metode rank reciprocal method. Data tersebut akan dianalisis lebih lanjut ke tahap matching stage dengan menggunakan teknik IE Matrix. Setelah diketahui rekomendasi bisnis warteg berada pada bagian tertentu dan dapat dikembangkan maka analisis dilakukan dengan teknik TOWS.

3) Hasil analisis TOWS untuk pemilihan strategi pengembangan rumah makan padang maka dilanjutkan pada analisis quantitative strategic planning matrix untuk mencari rekomendasi strategi terbaik yang merupakan tahap akhir penentuan keputusan strategi.

Analisis lingkungan eksternal, didasarkan pada variabel sosial ekonomi, pemerintahan (perizinan), dan lingkungan industri. Secara rinci data terkait faktor eksternal secara rinci dapat dilihat pada tabel berikut: 


\section{Tabel 2 . Faktor Kunci Berdasarkan Variabel Lingkungan Eksternal

\begin{tabular}{cl}
\hline Variabel & \multicolumn{1}{c}{ Faktor eksternal kunci } \\
\hline Sosial Ekonomi & Pendapatan masyarakat menurun \\
& Perubahan selera masyarakat yang cepat
\end{tabular} \\ Pemerintahan Perizinan Usaha \\ Perizinan Kesehatan \\ Kenaikan harga barang \\ Lingkungan Industri Persaingan bisnis sejenis \\ Persaingan bisnis makanan franchise luar negeri \\ Transformasi teknologi informasi \\ Sumber: Data primer diolah (2021).}

Lingkungan internal diproksi dengan variabel proses produksi warteg, keuangan dan operasi bisnis Data variabel penelitian terkait faktor internal secara rinci tertera pada tabel berikut ini:

\section{Tabel 3. Faktor Kunci Berdasarkan Variabel Internal}

\begin{tabular}{ll}
\hline \multicolumn{1}{c}{ Variabel } & \multicolumn{1}{c}{ Faktor Eksternal Kunci } \\
\hline Produksi & $\begin{array}{l}\text { Tidak dapat melakukan stok } \\
\text { Bahan baku harus segar }\end{array}$ \\
Operangan & $\begin{array}{l}\text { Ketersediaan modal } \\
\text { Pengelolaan Keuangan }\end{array}$ \\
& $\begin{array}{l}\text { Menu yang beragam } \\
\text { Jam operasi } \\
\text { Kebersihan } \\
\text { Lokasi bisnis } \\
\text { Sistem pembayaran }\end{array}$ \\
\hline
\end{tabular}

\section{HASIL DAN PEMBAHASAN}

Berdasarkan analisis validitas dan reliabilitas atas faktor yang dianalisis diperoleh nilai KMO lebih besar dari 0,5, nilai cronbach alpha lebih dari 0,6 dan tingkat signifikasi lebih kecil dari 0,05. Kriteria uji didasarkan pada paper dari Hendryadi dan Kowsalya et al (Hendryadi, 2017; Kowsalya, Lakshmi, \& Suresh, 2012). Nilai tersebut menunjukkan bahwa semua konstruk valid dan realibel. Sehingga analisis SWOT dapat dilanjutkan. Data rinci penjelasan keterangan di atas dapat dilihat pada tabel berikut:

Tabel 4. Hasil Uji Face Validity \& Realibility Atas Faktor

\begin{tabular}{llll}
\hline $\begin{array}{c}\text { Key } \\
\text { Factors }\end{array}$ & $\begin{array}{c}\text { Kaiser-Meyer-Olkin Measure } \\
\text { of Sampling Adequacy. }\end{array}$ & \multicolumn{1}{c}{ Sig. } & \multicolumn{1}{c}{$\begin{array}{c}\text { Realibility Test } \\
\text { Cronbach's Alpha }\end{array}$} \\
\hline Peluang & 0,728697531641845 & 0,00132128477188666 & 0,714810017271162 \\
Ancaman & 0,749453774914929 & 0,0000884950181878995 & 0,74526207956292 \\
Kekuatan & 0,69420474450017 & $2,87493484992741 \mathrm{E}-14$ & 0,839667792792796 \\
Kelemahan & 0,749576821780426 & $1,4191887162321 \mathrm{E}-10$ & 0,827073552425665 \\
\hline
\end{tabular}

Sumber : Data primer diolah (2021) 


\subsection{Analisis SWOT}

Berdasarkan analisis lingkungan eksternal dan internal diperoleh hasil rekapitulasi atas empat kelompok kunci: peluang, ancaman, kekuatan dan kelemahan. Setelah dikelompokkan maka tim panel ahli diminta untuk menilai bobot masing-masing faktor kunci pada seluruh obyek penelitian. Data rinci mengenai faktor kunci dan nilai bobotnya tertera pada tabel berikut ini:

Tabel 5. Tabel Eksternal-Internal Warteg

\begin{tabular}{|c|c|c|c|c|c|c|}
\hline \multirow{2}{*}{ No } & \multirow{2}{*}{ Faktor kunci } & \multirow{2}{*}{ Bobot } & \multicolumn{2}{|c|}{ Warteg Putra Kuningan } & \multicolumn{2}{|c|}{ Warteg Berkah Bahari } \\
\hline & & & Rating & Bobot x Rating & Rating & Bobot x Rating \\
\hline & Peluang & & & & & \\
\hline 1. & Jam operasional 24 Jam & 0,17 & 3 & 0,51 & 3 & 0,51 \\
\hline 2. & Harga bersaing & 0,11 & 4 & 0,46 & 3 & 0,34 \\
\hline 3. & Bahan makanan segar & 0,06 & 3 & 0,17 & 3 & 0,17 \\
\hline 4. & Banyak varian menu & 0,07 & 3 & 0,20 & 3 & 0,20 \\
\hline \multirow[t]{2}{*}{5.} & Tempat yang bersih dan nyaman & 0,09 & 3 & 0,26 & 3 & 0,26 \\
\hline & Tantangan & & & & & \\
\hline 6. & Kurangnya kebersihan dan kenyamanan & 0,04 & 1 & 0,04 & 2 & 0,09 \\
\hline 7. & Selera konsumen yang berubah-ubah & 0,03 & 1 & 0,03 & 2 & 0,07 \\
\hline 8. & Izin operasional pembukaan usaha & 0,34 & 2 & 0,68 & 1 & 0,34 \\
\hline 9. & Perkembangan teknologi pembayaran & 0,05 & 1 & 0,05 & 2 & 0,10 \\
\hline \multirow[t]{2}{*}{10.} & Banyak waralaba makanan cepat saji (banyak pesaing) & 0,04 & 2 & 0,08 & 1 & 0,04 \\
\hline & Kekuatan & & & & & \\
\hline 1. & Harga yang murah & 0,34 & 4 & 1,37 & 4 & 1,37 \\
\hline 2. & Lokasi strategis berada dipinggir jalan raya & 0,11 & 4 & 0,46 & 3 & 0,34 \\
\hline 3. & Full music dilengkapi televisi & 0,07 & 3 & 0,20 & 3 & 0,20 \\
\hline 4. & Menu makanan rumahan & 0,17 & 3 & 0,51 & 4 & 0,68 \\
\hline \multirow[t]{2}{*}{5.} & Jam buka yang panjang & 0,09 & 3 & 0,26 & 3 & 0,26 \\
\hline & Kelemahan & & & & & \\
\hline 1. & Tempat sempit dan tidak cozy & 0,06 & 1 & 0,06 & 1 & 0,06 \\
\hline 2. & Segmentasi kelas menengah bawah & 0,04 & 3 & 0,13 & 2 & 0,09 \\
\hline 3. & Tampilan makanan kurang menarik & 0,05 & 2 & 0,10 & 3 & 0,15 \\
\hline 4. & Banyak warteg kompetitor & 0,04 & 1 & 0,04 & 2 & 0,08 \\
\hline 5. & Bahan baku mudah basi & 0,03 & 3 & 0,07 & 1 & 0,03 \\
\hline
\end{tabular}

Sumber : Data primer diolah (2021)

Pengamatan atas lingkungan eksternal dan internal dalam suatu bisnis diperlukan untuk dapat menjalankan bisnis dalam jangka panjang dan menang atas persaingan. Data di atas merupakan data akurat yang dapat menjadi materi evaluasi dan memonitor kondisi bisnis warteg. Hasil penelitian menunjukkan bahwa pengamatan lingkungan eksternal warteg Putra Kuningan lebih baik dibandingkan warteg Berkah Bahari. Keunggulan eksternal warteg ini berasal dari faktor harga dan izin usaha. Sementara keunggulan internal Warteg Berkah Bahari lebih unggul dibanding warteg Putra Kuningan. Keunggulan berasal dari faktor menu makanan yang lebih beragam serta tampilan makanan yang lebih menarik dan lebih teratur dibandingkan warteg Putra Kuningan.

Pengamatan lingkungan eksternal terhadap analisis peluang yang memiliki bobot terbesar adalah jam operasional warteg 24 jam. Faktor ini memang menjadi peluang karena dapat menyediakan makanan kapan pun dibutuhkan oleh konsumen di perkotaan. Sedangkan kompetitor lainnya kesulitan menghadapi permintaan sampai dengan dua puluh empat jam. Hal ini didukung oleh penelitian yang menunjukkan bahwa jam operasional warteg terbukti memiliki pengaruh yang signifikan terhadap pendapatan pemilik (S. A. Santoso, 2019). Banyak studi yang dilakukan mengenai jam buka bisnis akibat pandemi covid-19, dimana rata-rata bisnis makanan membuka outlet-nya dengan durasi yang lebih 
lama (sekitar dua jam lebih panjang dibandingkan saat sebelum pandemi covid-19) (Chowdhury, Sarkar, Paul, \& Moktadir, 2020; Fairlie, 2020).

Analisis lingkungan eksternal terkait tantangan yang dihadapi oleh bisnis warteg dengan bobot terbesar (nilai 0,34) adalah izin operasional. Kedua warteg obyek penelitian belum memiliki izin usaha (karena bisnis masih pada skala mikro), izin halal dari MUI, izin kesehatan dan keselamatan pangan dari Depkes. Sementara konsumen saat ini sudah sangat mengandalkan pilihan makanan mereka yang memiliki izin-izin tersebut di atas. Bisnis kecil dan menengah memiliki peran besar dalam menjaga keamanan pangan (Galli et al., 2020). Ketersediaan informasi mengenai keamanan, keselamatan dan kesehatan pangan menjadi salah satu faktor nilai tambah bagi suatu produk (Chen, Ellett, Phillips, \& Feng, 2021; Hernández et al., 2021; M.D. Novianti \& Susanto, 2018; Zhang \& Li, 2012)). Sehingga penerapan strategi penjagaan keamanan pangan menjadi penting (Borda, Mihalache, Dumitraşcu, Gafițianu, \& Nicolau, 2021).

Pengamatan lingkungan internal terkait analisis kekuatan warteg yang memiliki bobot terbesar adalah pada faktor harga yang murah. Faktor ini memang menjadi penentu dalam pengambilan keputusan konsumen dalam membeli makanan. Terlebih lagi kondisi perekonomian saat ini yang terus menekan daya beli masyarakat. Harga yang murah ditunjang oleh beragamnya menu rumahan mendorong konsumen untuk melakukan tindakan pembelian. Keandalan penetapan harga murah sangat mempengaruhi keputusan pembelian konsumen (T. A. Santoso, 2014). Sehingga produk warteg tidak asing dan terkenal murah (M.D. Novianti \& Susanto, 2018). Bila dikaji dari aspek hukum syariah, suatu bisnis harus menerapkan takaran dan harga yang sesuai dan sama pada semua konsumen. Sehingga bisnis ini dapat dipercaya oleh konsumen dalam jangka panjang (Teguh, Ramdan, Encep, \& Rojak, 2018). Kekuatan ini harus terus dipertahankan karena dapat menekan persaingan dengan sesama bisnis makanan dari luar negeri. Upaya ini memerlukan upaya sinergi dan keberpihakan semua pemangku kepentingan yaitu pemerintah dan masyarakat demi menjaga keberlangsungan bisnis warteg yang merupakan bisnis asli Indonesia (Meilasari-Sugiana, Susanto, \& Novianti, 2019).

Analisis lingkungan internal mengenai faktor kelemahan warteg, didapatkan hasil bahwa faktor kritis dengan bobot tertinggi adalah tempat yang tidak bersih dan cozy seperti restoran atau outlet makanan dari luar negeri. Hal ini jika tidak diantisipasi dengan baik, akan menekan kemampuan bersaing warteg. Hal ini sesuai dengan penelitian yang menunjukkan bahwa kebersihan dan kenyamanan tempat makan akan mempengaruhi persepsi konsumen (Seung, 2012; Marković, Raspor, \& Dorčić, 2011). Persepsi itu adalah semakin bersih tempat makan semakin baik kualitas produk yang dijual (Serhan \& Serhan, 2019).

Analisis Eksternal-Internal menunjukkan nilai warteg Berkah Bahari adalah 2,12 dan 3,25 dan nilai warteg Putra Kuningan atas lingkungan eksternal adalah 2,48 dan lingkungan internal bernilai 3,18. Pada tahap pencocokan, nilai tersebut harus diaplikasikan dengan matrik El. Matrik ini dapat menentukan posisi warteg atas dasar 9 sel keputusan strategi yang berbeda-beda sesuai nilai Eksternal-Internalnya (EI) (David, 2011). 


\begin{tabular}{|c|c|c|c|c|c|}
\hline \multirow{5}{*}{$\begin{array}{l}\text { Total } \\
\text { Skor } \\
\text { Faktor } \\
\text { Eksternal }\end{array}$} & \multirow[b]{3}{*}{ Tinggi } & \multirow[b]{2}{*}{4,0} & Kuat & $\begin{array}{l}\text { otal Skor Faktor Int } \\
\text { Rata-Rata }\end{array}$ & Lemah \\
\hline & & & 3,0 & 2,0 & 1,0 \\
\hline & & 3,0 & $\begin{array}{c}1 \\
\text { Growth \& } \\
\text { Build }\end{array}$ & $\begin{array}{c}2 \\
\text { Growth \& Build }\end{array}$ & $\begin{array}{c}3 \\
\text { Hold \& } \\
\text { Maintain }\end{array}$ \\
\hline & Menengah & 2,0 & $\begin{array}{c}4 \\
\text { Growth \& } \\
\text { Build }\end{array}$ & $\begin{array}{c}5 \\
\text { Hold \& } \\
\text { Maintain }\end{array}$ & $\begin{array}{c}6 \\
\text { Retrenchment }\end{array}$ \\
\hline & Sedang & 1,0 & $\begin{array}{c}7 \\
\text { Hold \& } \\
\text { Maintain }\end{array}$ & $\begin{array}{c}8 \\
\text { Retrenchment }\end{array}$ & $\begin{array}{c}9 \\
\text { Retrenchment }\end{array}$ \\
\hline
\end{tabular}

\section{Gambar 2.Matriks Eksternal-Internal Untuk Pengembangan Bisnis Warteg}

Sumber :(David, 2011)

Keterangan Gambar:

: Posisi Warteg Berkah Bahari

: Posisi Warteg Putra Kuningan

Tahap pencocokan dengan matriks El menunjukkan kedua warteg berada pada wilayah empat dengan rekomendasi strateginya adalah dibangun dan dikembangkan. Dari data di atas, harus dianalisis lebih lanjut dengan analisis TOWS untuk dapat menghasilkan rekomendasi strategi bisnis yang lebih rinci dan spesifik.

\subsection{Analisis TOWS}

Analisis TOWS akan menghasilkan strategi kombinasi dari kekuatan internal dengan peluang eksternal, strategi kombinasi kelemahan internal dengan peluang eksternal, strategi kombinasi kekuatan internal dengan ancaman eksternal, serta kombinasi strategi antara kelemahan internal dengan ancaman eksternal (David, 2011). Berdasarkan hasil penelitian, didapatkan analisis TOWS sesuai tabel berikut:

Tabel 6. Hasil Analisis TOWS

\begin{tabular}{|c|c|c|}
\hline $\begin{array}{l}\text { Eksternal- } \\
\text { Internal }\end{array}$ & Strength & Weekness \\
\hline Opportunity & $\begin{array}{l}\text { 1. Harga yang terjangkau semua } \\
\text { kalangan (S1:O2) } \\
\text { 2. Lokasi strategis dan tempat makan } \\
\text { yang bersih dan nyaman, full music } \\
\text { dan tersedia televisi ( } 2 ; \mathrm{S} 5 ; 05) \\
\text { 3. Makanan segar dan menu bervariasi } \\
\text { (S4;03:04) } \\
\text { 4. Jam Operasional yang panjang } \\
\text { (S5;01) }\end{array}$ & $\begin{array}{l}\text { 1. Menyediakan tempat makan yang bersih } \\
\text { dan nyaman (W1;05) } \\
\text { 2. Memperluas segmen pasar dengan } \\
\text { makanan segar dan bervariasi } \\
\text { (W3;W5;05;04) } \\
\text { 3. Harga yang terjangkau, jam operasional } \\
\text { yang } 24 \text { jam untuk menekan kompetisi } \\
\text { menghabiskan stok (W5;W5;01;05) }\end{array}$ \\
\hline Thread & $\begin{array}{l}\text { 1. Membuat harga terjangkau dengan } \\
\text { platform teknologi pembayaran } \\
(\mathrm{S} 1 ; \mathrm{T} 4)\end{array}$ & $\begin{array}{l}\text { 1. Membuat tempat makan yang menarik } \\
\text { konsumen, bersih dan nyaman } \\
\text { (W1;T1:T5) }\end{array}$ \\
\hline
\end{tabular}


2. Menjaga kebersihan dan kenyamanan dengan mempertahankan lokasi strategis di pinggir jalan dan menyediakan life music dan TV dan memperoleh izin usaha, halal MUI, izin kebersihan dan keamanan pangan Depkes (S2;S3;T1;T3)

3. Membuat menu makanan yang variatif untuk mengantisipasi selera konsumen yang berubah dan jam operasional yang panjang $(\mathrm{S} 4 ; \mathrm{S} 5 ; \mathrm{T} 2 ; \mathrm{T} 5)$
2. Memperluas segmen dengan mengembangkan teknologi pembayaran (W2;T4)
3. Menu makanan yang variatif agar memenuhi selera konsumen yang berubah-ubah dan mengurangi persaingan dengan bisnis sejenis dan bisnis fast food waralaba (W3;W4;T2;T3;T5)

4. Mengurus izin operasional (izin usaha, sertifikat halal MUI, izin kebersihan Depkes) (W4;T3)

Sumber: Data primer diolah (2021)

Rekapitulasi tabel TOWS di atas, menghasilkan strategi bisnis yaitu:

1) Menyediakan tempat makan yang bersih, nyaman, full music, TV dan lokasi yang memiliki izin, strategis dan jam operasional 24 jam,

2) Membuat menu makanan yang berbahan segar dan bervariasi setiap hari, dan

3) Menetapkan harga murah dan mengembangkan teknologi pembayaran.

Ketiga rekomendasi strategi tersebut di atas harus kembali dinilai total ketertarikan masing-masing strategi, oleh panel ahli untuk dapat merumuskan quantitative strategy planing matrix (QSPM). Hasil analisis secara rinci dapat dilihat pada tabel berikut:

\section{Tabel 7. Attractive Score Strategi Pengembangan Bisnis Warteg}

\begin{tabular}{|c|c|c|}
\hline No & Alternatif Strategi & $\begin{array}{l}\text { Total Attractive } \\
\text { Score (TAS) }\end{array}$ \\
\hline S1 & $\begin{array}{l}\text { Menyediakan tempat makan yang bersih, nyaman, full music, TV } \\
\text { dan lokasi yang memiliki izin, strategis dan jam operasional } 24 \text { jam }\end{array}$ & 6,69 \\
\hline S2 & $\begin{array}{l}\text { Membuat menu makanan yang berbahan segar dan bervariasi } \\
\text { setiap hari }\end{array}$ & 6,39 \\
\hline S3 & $\begin{array}{l}\text { Menetapkan harga murah dan mengembangkan teknologi } \\
\text { pembayaran }\end{array}$ & 6,66 \\
\hline
\end{tabular}

Sumber: Data primer diolah (2021)

Nilai strategi "menyediakan tempat makan yang bersih, nyaman, full music, TV dan lokasi yang memiliki izin, strategis dan jam operasional 24 jam" adalah strategi yang harus dilaksanakan terlebih dahulu karena memiliki nilai tertinggi. Semua kondisi tersebut dalam manajemen operasional termasuk dalam kategori service scape. Service scape seperti halnya atmosfer warteg akan sangat mempengaruhi preferensi dan keputusan pembelian oleh konsumen (Kanyan, Ngana, \& Voon, 2016). Kondisi ini menjadi perhatian utama karena konsumen generasi $Z$ sangat mementingkan service scape. Semakin menarik hal tersebut maka akan semakin loyal konsumen (Voon, 2012). Strategi kedua yang dapat diterapkan adalah upaya untuk secara terus menerus melakukan inovasi menu makanan kekinian dengan bahan segar dan peduli pada kesehatan. Hal ini sejalan dengan rekomendasi penelitian Muttalib mengenai pola pengembangan bisnis makanan UMKM di kota Mataram, bahwa pelaku bisnis harus selalu kreatif dan inovatif dan terus menerus meningkatkan mutu produk yang dihasilkan (Muttalib, 2017). Strategi ketiga yang harus 
dilakukan warteg agar bisnisnya berkembang adalah menerapkan harga yang sesuai di semua lapisan masyarakat serta mengikuti perkembangan teknologi pembayaran secara online dan real time. Penerapan teknologi digital bagi usaha mikro, kecil, dan menengah dapat menjadi strategi penting agar bisnis dapat bertahan dalam persaingan bisnis (Latifi, Nikou, \& Bouwman, 2021; Meilasari-Sugiana et al., 2019; Hassan, Nadzim, \& Shiratuddin, 2015). Strategi kedua dan ketiga dapat diupayakan dengan menerapkan konsep circular economy yang mengacu pada supply chain management dan zero-waste. Pemasok membutuhkan pemilik Warteg sebagai pembeli, sedangkan pemilik Warteg membutuhkan pemasok untuk mendukung mereka dengan informasi dan pengetahuan, sebagai sumber berharga dalam pembuatan keputusan pembelian bahan makanan yang segar dan sehat (Sunardi, 2012).

\section{PENUTUP}

\subsection{Kesimpulan}

Berdasarkan hasil penelitian diperoleh kesimpulan bahwa strategi yang harus dilakukan oleh pemilik warteg sekitar kampus IBI Kosgoro 1957 agar bisnisnya berkembang adalah menyediakan tempat makan yang bersih, nyaman, full music, TV dan lokasi yang memiliki izin, strategis dan jam operasional 24 jam, membuat inovasi menu makanan yang segar dan bervariasi setiap hari dan menetapkan harga terjangkau bagi semua lapisan masyarakat dan mengembangkan teknologi pembayaran melalui platform digital.

\subsection{Saran}

Pemilik bisnis warteg di sekitar kampus IBI Kosgoro 1957 dapat dibimbing agar dapat menjalankan rekomendasi strategi penelitian ini. Dengan tujuan menjalin sirkuler ekonomi antara warteg-mahasiswa-kampus-masyarakat sekitar sehingga bisnisnya dapat berkembang lebih besar.

\section{DAFTAR PUSTAKA}

A'yun, T. A. Q. (2017). Perencanaan Pengembangan Usaha Rumah Makan Mabuk Mancing di Kelurahan Lesanpuro, Kecamatan Kedungkandang Kota Malang, Jawa Timur. Universitas Brawijaya. Retrieved from http://repository.ub.ac.id/8316/1/Tedy Agvita Qurota A'yun.pdf

Andriyanty, R., \& Wahab, D. (2019). PREFERENSI KONSUMEN GENERASI Z TERHADAP KONSUMSI PRODUK DALAM NEGERI. ETHOS (Jurnal Penelitian Dan Pengabdian), 7(2), 280-296.

Asytuti, R. (2015). Pengusaha Warung Tegal di Jakarta (Pendekatan Modal Sosial). Jurnal Hukum Isma (JHI), 13(1), 13-24. Retrieved from http://ejournal.iainpekalongan.ac.id/index.php/jhi/article/view/492/491

Awaloedin, D. T., Sazali, Nurhilaludin, \& Hanifa, M. (2020). Strategi Menghadapi Dampak Pandemi covid 19 terhadap Usaha Kecil dan Menengah. Universitas Nasional. Jakarta. Retrieved from http://repository.unas.ac.id/843/1/Penelitian Pandemi Covid 19 final 29 mei-2-dikonversi.pdf

Badan Ekonomi Kreatif RI. (2020). Laporan Kinerja Badan Ekonomi Kreatif Tahun 2019. Jakarta. 
Badan Pusat Statistik. (2020). Buku Data Statistik Sektoral Provinsi DKI Jakarta Tahun 2020.

Borda, D., Mihalache, O. A., Dumitraşcu, L., Gafițianu, D., \& Nicolau, A. I. (2021). Romanian consumers' food safety knowledge, awareness on certified labelled food and trust in $\begin{array}{llll}\text { information } & \text { sources. } & \text { Food }\end{array}$ https://doi.org/10.1016/j.foodcont.2020.107544

Charles, N. A., Ojera, P. B., \& David, O. (2015). Factors influencing choice of strategic management modes of small enterprises. Journal of Innovation and Entrepreneurship, 4(1). https://doi.org/10.1186/s13731-014-0016-y

Chen, H., Ellett, J. K., Phillips, R., \& Feng, Y. (2021). Small-Scale Produce Growers' Barriers and Motivators to Value-Added Business: Food Safety and Beyond. Food Control, 108192. https://doi.org/10.1016/j.foodcont.2021.108192

Chowdhury, M. T., Sarkar, A., Paul, S. K., \& Moktadir, M. A. (2020). A case study on strategies to deal with the impacts of COVID-19 pandemic in the food and beverage industry. Operations Management Research. https://doi.org/10.1007/s12063-02000166-9

David, F. R. (2011). Strategic Management. Concepts and Cases. 13th Edition. Prentice Hall.

Draper, A. (1996). Street foods in developing countries: The potential for micronutrient fortification. London School of Hygiene and Tropical Medicine, 1-74.

Fairlie, R. W. (2020). The Impact of Covid-19 on Small Business Owners: Evidence of EarlyStage Losses From the April 2020 Current Population Survey. NBER Working Paper Series, (May), 1-23. Retrieved from http://www.nber.org/papers/w27309

Galli, F., Grando, S., Adamsone-Fiskovica, A., Bjørkhaug, H., Czekaj, M., Duckett, D. G., ... Brunori, G. (2020). How do small farms contribute to food and nutrition security? Linking European small farms, strategies and outcomes in territorial food systems. Global Food Security, 26(November 2019). https://doi.org/10.1016/j.gfs.2020.100427

Hassan, S., Nadzim, S. Z. A., \& Shiratuddin, N. (2015). Strategic Use of Social Media for Small Business Based on the AIDA Model. Procedia - Social and Behavioral Sciences, 172, 262-269. https://doi.org/10.1016/j.sbspro.2015.01.363

Hendryadi, H. (2017). Validitas Isi: Tahap Awal Pengembangan Kuesioner. Jurnal Riset Manajemen Dan Bisnis (JRMB) Fakultas Ekonomi UNIAT, 2(2), 169-178. https://doi.org/10.36226/jrmb.v2i2.47

Hernández, P. A., Galli, F., Prosperi, P., Šūmane, S., Duckett, D., \& Almaas, H. E. (2021). Do small food businesses enable small farms to connect to regional food systems? Evidence from 9 European regions. Global Food Security, 29(July 2020). https://doi.org/10.1016/j.gfs.2021.100505

Hiemstra, A. M. F., Van Der Kooy, K. G., \& Frese, M. (2006). Entrepreneurship in the street food sector of Vietnam - Assessment of psychological success and failure factors. Journal of Small Business Management, 44(3), 474-481. https://doi.org/10.1111/j.1540-627X.2006.00183.x

Hilmi, M. (2020). Street food vendors' entrepreneurial marketing characteristics and practices from 12 countries: what lessons can be learnt for improving food marketing in BOP/Subsistence marketplaces. Middle East Journal of Agriculture Research, 321348. https://doi.org/10.36632/mejar/2020.9.2.27 
Kanyan, A., Ngana, L., \& Voon, B. H. (2016). Improving the Service Operations of Fast-food Restaurants. Procedia - Social and Behavioral Sciences, 224(August 2015), 190-198. https://doi.org/10.1016/j.sbspro.2016.05.439

Karel, S., Adam, P., \& Piszezur, R. (2013). Strategic Planning and Business Performance of Micro, Small and Medium-Sized Enterprises. Journal of Competitiveness, 5(4), 5772. https://doi.org/10.7441/joc.2013.04.04

Khamdevi, M., \& Nasution, I. (2014). Studi Karakteristik Arsitektur Khas Pada Warung Tegal Di Jabodetabek. Ja! Ubl, 1-9. Retrieved from http://jurnal.ubl.ac.id/index.php/ja/article/view/529

Knox, A. J., Bressers, H., Mohlakoana, N., \& De Groot, J. (2019). Aspirations to grow: when micro- and informal enterprises in the street food sector speak for themselves. Journal of Global Entrepreneurship Research, 9(1). https://doi.org/10.1186/s40497-019-01617

Kowsalya, D. N., Lakshmi, V., \& Suresh, K. P. (2012). Development and Validation of a Scale to assess Self-Concept in Mild Intellectually Disabled Children. International J. Soc. Sci. \& Education, 2(4), 2223-4934.

Latifi, M.-A., Nikou, S., \& Bouwman, H. (2021). Business model innovation and firm performance: Exploring causal mechanisms in SMEs. Technovation, 107(May 2020), 102274. https://doi.org/10.1016/j.technovation.2021.102274

Lawshe, C. H. (1975). A Quantitative Approach To Content Validity. Personnel Psychology, 28(4), 563-575. https://doi.org/10.1111/j.1744-6570.1975.tb01393.x

Marković, S., Raspor, S., \& Dorčić, J. (2011). What Are the Key Dimensions of Restaurant Service Quality? an Empirical Study in the City Restaurant Settings. Tourism in South East Europe 2011, 1, 235-249. Retrieved from https://bib.irb.hr/datoteka/574469.MarkoviRaspor_Dori.-

restaurant_service_quality.pdf

Meilasari-Sugiana, A., Susanto, T., \& Novianti, M. (2019). Jakarta's WARTEG food stall phenomenon: Constraints and opportunities for integration. Human Geographies, 13(2), 187-207. https://doi.org/10.5719/hgeo.2019.132.5

Mohajan, H. K. (2017). Two Criteria for Good Measurements in Research: Validity and Reliability. Annals of Spiru Haret University. Economic Series, 17(4), 59-82. https://doi.org/10.26458/1746

Muttalib, A. (2017). POLA PENGEMBANGAN USAHA MIKRO KECIL DAN MENENGAH (UMKM) DI KOTA MATARAM TAHUN 2016. JISIP, 1(2), 168-178. Retrieved from http://ejournal.mandalanursa.org/index.php/JISIP/article/download/252/243

Nirathron, N. (2006). Fighting Poverty from the Street: A Survey of Street Food Vendors in Bangkok. Informal Economy, Poverty and Employment Thailand Series (Vol. 1). Retrieved from https://staging.ilo.org/wcmsp5/groups/public/---asia/---robangkok/documents/publication/wcms_bk_pb_128_en.pdf

Novianti, M.D., \& Susanto, T. (2018). Identifying Warung Tegal Development Factors: a Preliminary Analysis on Warung Tegal in Jabodetabek, Indonesia. Russian Journal of Agricultural and Socio-Economic Sciences, 85(1), 107-112. https://doi.org/10.18551/rjoas.2018-12.14

Novianti, Mirsa Diah, Susanto, T., Hatta, H., \& Johannes, R. (2018). Kajian Identifikasi Faktor Untuk Pengembangan Usaha Warung Tegal ( Warteg ) Masuk Mall ( Studi 
Kasus Di Jabodetabek ). Journal of Entrepreneurship, Management, and Industry (JEMI), 1(September), 143-150. Retrieved from http://jurnal.bakrie.ac.id/index.php/JEMl/article/download/1818/1433

Santoso, S. A. (2019). Pengaruh Variasi Menu, Harga, Jam Kerja, Dan Lama Usaha Terhadap Pendapatan Warung Tegal Di Kecamatan Ciputat Timur. Repository.Uinjkt.Ac.ld. UIN Syarif Hidayatullah Jakarta. Retrieved from http://repository.uinjkt.ac.id/dspace/handle/123456789/47938

Santoso, T. A. (2014). Pengaruh Harga Dan Kualitas Produk Terhadap Keputusan Pembelian. Fakultas Ekonomika dan Bisnis. Universitas Dipenegoro. Retrieved from http://eprints.ums.ac.id/66618/11/NASKAH PUBLIKASI.pdf

Sarwono, H. A. (2015). Profil Bisnis Usaha Mikro, Kecil Dan Menengah (Umkm). Bank Indonesia dan LPPI.

Serhan, M., \& Serhan, C. (2019). The Impact of Food Service Attributes on Customer Satisfaction in a Rural University Campus Environment. International Journal of Food Science, 2019. https://doi.org/10.1155/2019/2154548

Seung, A. . (2012). Customer Perceptions of Restaurant Cleanliness: A Cross Cultural Study. Virginia Polytechnic Institute and State University.

Sunardi, O. (2012). Knowledge Sharing in the Supply Chain Network: Findings From Selected "Warung Tegal" Business in B Andung, 01 No. 04, 382-388.

Teguh, A., Ramdan, M., Encep, F., \& Rojak, A. (2018). Pandangan Hukum Islam Terhadap Penetapan Harga Yang Berbeda Dalam Jual Beli di Rumah Makan Prasmanan ( Studi Kasus di Warteg Lingkungan Kampus UNISBA ). In Hukum Ekonomi Syariah (pp. 1068-1072).

Voon, B. H. (2012). Role of Service Environment for Restaurants: The Youth Customers' Perspective. Procedia - Social and Behavioral Sciences, 38(December 2010), 388395. https://doi.org/10.1016/j.sbspro.2012.03.361

Yaghmaei F. (2003). Content validity and its estimation. Journal of Medical Education, 3(1), 25-27. https://doi.org/10.22037/jme.v3i1.870

Zhang, M., \& Li, P. (2012). RFID Application Strategy in Agri-Food Supply Chain Based on Safety and Benefit Analysis. Physics Procedia, 25, 636-642. https://doi.org/10.1016/j.phpro.2012.03.137 